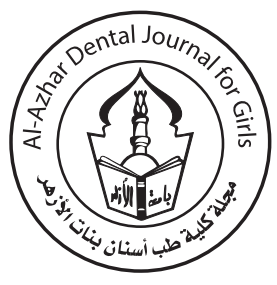

\title{
Effect of Different Bar Attachment and Clip Materials on Retention Force for Mandibular Implant Supported Overdentures (An Invitro Study)
}

\author{
Mostafa A.Y. Hammas ${ }^{(1)}$, Maged G.El-Saadawy ${ }^{(2)}$ and Ahmed H. El-Agamy ${ }^{(3)}$
}

Codex : 23/1804

azhardentj@azhar.edu.eg

http://adjg.journals.ekb.eg

\section{KEYWORDS}

Bar attachment, mandibular overdentures, clip materials, retention force.

\begin{abstract}
Objective: to evaluate the effect of bar and clip attachment systems with different materials on retention forces for two implant supported mandibular over dentures after wear simulation. Materials and methods: An edentulous mandibular model was constructed incorporating 2 parallel implants placed in the canine regions. Attachments were embedded in ametal-reinforced experimental over denture designed to be dislodged from the model by a universaltesting machine. Tensile dislodging force was applied to the overdenture at a cross-head speed of $50 \mathrm{~mm} / \mathrm{min}$. Four over dentures were constructed for the attachment systems. The attachments evaluated were metal bar with clip from polyoxymethylene (POM), metal bar with clip from polyetheretherketon (PEEK), (PEEK) bar with (POM) clip and(PEEK) barwith (PEEK) clip. Peak loadto-dislodgement was measured. Retention strength values $(\mathrm{N})$ were recorded initially and after 270, 540, 810 and 1080 cycles of insertion and removal simulating 0, 3, 6, 9 and 12 months of denture using repictively. Repeated measure ANOVA was used to compare between more than two groups for dependent samples while One-way ANOVA was used to compare between more than two groups for independent samples. The significance level was set at $\mathrm{P} \leq 0.05$. Statistical analysis was performed with IBM ${ }^{\circledR}$ SPSS $®$ Statistics Version 20 for Windows. Results: A statistically significant difference was found between (Metal bar and POM clip), (Metal bar and PEEK clip), (PEEK bar and POM clip) and (PEEK bar and PEEK clip) where ( $\leq \leq 0.001)$. The highest mean value of retention was found in (PEEK bar and PEEK clip) followed by (Metal bar and PEEK clip) and (PEEK bar and POM clip) while the least mean value of retention was found in (Metal bar and POM clip).Conclusion: Attachments generally demonstrated significantly decreased retention strength values as the cycle's number increased. POM as well as PEEK materials may fulfill the requirements of retentive clips on metal or PEEK bars. The invitro performance of retentive clips made of PEEK is superior to those made of POM.
\end{abstract}

- Paper extracted from master thesis entitled

1. Assistant Professor and Acting Head of Prosthodontics Department, Faculty of Dental Medicine, Al-Azhar University, Assuit Branch.

2. Lecturer of Prosthodontics, Faculty of Dental Medicine, Al-Azharuniversity, Assuit Branch.

3. Demonestrator of Prosthodontics Department, Faculty of Dental Medicine, Al-Azharuniversity, Assuit Branch. 


\section{INTRODUCTION}

Until the introduction of osseointegrated implantsupported prosthesis, complete dentures were the only available treatment for edentulous patients. ${ }^{(1)}$ It is well known that with the use of conventional complete mandibular denture, there is ongoing loss of the superior surface of the body of the mandible. ${ }^{(2)}$ Subsequently, atrophy of the edentulous mandible takes place accompanied by reduction in retention, stability and load bearing capacity of the complete denture resulted in compromised function and loss of the facial form. ${ }^{(3)}$ Treatment with dental implants has been proved to be predictable, reliable, effective and safe. ${ }^{(4)}$ Moreover, the use of dental implants and implant retained mandibular overdentures resulted in a significantly better chewing experience, masticatory performance, less complaints and higher overall satisfaction when compared with conventional complete denture. Also the use of osseointegrated root form implant helped toward restoration of the oral sensory function. ${ }^{(5)}$ The stability is superior when compared with that of the conventional denture. ${ }^{(6)}$ The retention is enhanced by the mechanical attachment to the implants, as the retentive implant supported overdenture remains in place during mandibular movement resulting in improved speech and oral function. ${ }^{(7)}$

Implant overdentures vary in design, according to the method of attachment and the amount of support to be derived from the implant and the ridge mucosa ${ }^{(6)}$ The choice of the attachment is dependent upon the retention required, jaw morphology, anatomy, mucosal ridge, oral function, and patient compliance for recall. ${ }^{(8)}$

Different attachment systems can be used for the retention of such implant-supported complete dentures: bar systems or single attachments as ball anchors, locators, magnets or telescopic crowns. These attachment systems differ in retention forces. ${ }^{(9)}$

The bar systems are used to splint the implants and they provide different degrees of movement towards the tissue, depending on the specific cross- sectional shape. ${ }^{(10)}$ There are two basic types of bar attachments based upon the shape and the action performed(A) Bar joints: allowed rotational and/or resilient movements between the two components. (B) Bar units: were comparatively rigid, allowing no movement between the sleeve and the bar. ${ }^{(11)}$ The component of the bar attached to the implants through screws, cement or a combination of both. ${ }^{(12)}$

Maximum dislodging forces or peak loads, defined as the maximum forces developed before complete separation of attachment components from teeth or implant abutments, can be used as proxy measurement of overdentures retention. It has been shown that the maximum force necessary to dislodge implant overdentures from their abutments varies with the number of insertion/removal cycles. ${ }^{(13)}$

Potential complications with attachments in mandibular overdenture treatment include loosening or breakage of clips or ball matrices, corrosion of magnets, loss of retention of clips and ball matrices and loosening of fixation screws of the bar or ball. ${ }^{(14)}$

The recent literature exhibits a high level of comfort and a good long-term stability with two interforaminal implants connected by bars. However, in the course of time the wear of the bar clip assembly has a negative effect on retention forces. In a clinical study, for egg-shaped bars, the retention force initially reached about $17 \mathrm{~N}$ and decreased after $3-5$ years of usage to about $12-14 \mathrm{~N}$ and after 10 years to $10 \mathrm{~N}$. This results in an increase in prosthetic maintenance service like tightening or changes of clips. ${ }^{(9)}$ Various in vitro studies tested the retention of attachment systems. But such results cannot be directly transferred to the clinical situation and in vivo measurements are needed. In vitro studies of the retention forces of bars led to controversial results. ${ }^{(9)}$

A study ${ }^{(15)}$ compared baseline and posttest retention of metal and plastic clip-retained overdenture analogs and monitored surface changes in bars and clips throughout the testing process. They noted that a statistically significant decrease 
in retention which varied in magnitude between sets was identified between the baseline values and those recorded at the end of cyclic loading.

A study ${ }^{(16)}$ quantified wear processes by measuring the retention force changes and the fitting tolerance at different prefabricated attachment systems to estimate the wear constancy and applicability in clinical practice. They noted that all types of anchors showed wear that led to a loss or to an increase in retention force at the beginning of the wear simulation. Anchors with a plastic retention insert showed the slightest changes in retention force. The wear does not have an effect on the fitting tolerance. Therefore, the plastic clips become more popular. While some wear of the plastic matrices occurs in vitro, clinically, wear of the metal patrices, that is, the bars or ball anchors is also observed. This wear may be caused by patient-related factors like quality and quantity of saliva or formation of calculus at the bar clip assembly. ${ }^{(9)}$

Polyoxymethylene (POM), also known as acetal resin,is reported to have a sufficiently high resilience and modulus of elasticity to allow its use in the manufacture of retentive clasps, connectors, and support elements for RPDs. ${ }^{(17)}$

Polyetheretherketone (PEEK) is a semicrystalline linear polycyclic aromatic thermoplastic that was first developed by a group of English scientists in 1978. In the 1980s, PEEK was commercialized for industrial applications, such as aircraft and turbine blades. By the late 1990s, PEEK became an important high-performance thermoplastic candidate for replacing metal implant components, especially in orthopedic and traumatic applications. $^{(18)}$

PEEK has excellent strength properties, it is insoluble in common solvents, and has a high resistance to wear and $\mathrm{g}$ irradiation. Besides, PEEK exhibits good biocompatibility in vitro and in vivo, causing neither toxic or mutagenic effects nor clinically significant inflammation. ${ }^{(19)} \mathrm{A}$ study ${ }^{(9)}$ tested whether the clinical performance of retentive clips made of poly-ether-ether-ketone (PEEK) is superior to those made of poly-oxy-methylene (POM).They founded that at baseline the median force for POM matrices was $6.89 \mathrm{~N}$ and for PEEK matrices $7.17 \mathrm{~N}$. After 6 months, the retention of POM decreased to $5.53 \mathrm{~N}$ and of PEEK to $6.42 \mathrm{~N}$. The retention force changed significantly over time without differences between POM and PEEK.

Materials used for attachments system should resist wear to provide constant retention forces in the course of time. Therefore, the aim of this invitro study is to evaluate the retention force of bar attachment systems with bars made from cobaltchromium (Co-Cr) or polyetheretherketon (PEEK) and clips made from (PEEK) or the standard clip material polyoxymethylene (POM) that used for retaining mandibular implant supported overdentures. The null hypothesis was that the trend of change in retentive force would not differ among the different bar attachments.

\section{MATERIALS AND METHODS}

A completely edentulous mandibular acrylic resin model was duplicated from a completely edentulous wax model obtained by pouring a lower impression for a completely mandibular edentulous stone model by molten wax. Two parallel implants were inserted in the canine's areas bilaterally in the model. (Fig: 1,a) The abutment patterns were waxed for copings.

Sixteen OT plastic bars were cut to the appropriate length between the waxed copings and each bar pattern was waxed directly to the implant abutment copings. After burnout of plastic components, eight of OT bars with their copings were casted using cobalt-chromium $(\mathrm{Co}-\mathrm{Cr})$ alloy and finished. Another eight OT bars were injected bypolyetheretherketon by for 2 press machine (for 2 press, bredent, Germany). Sixteen readymade yellow plastic clips were used. Eight of them were sprued, casted, burned out and injected by polyetheretherketon (PEEK) (Fig: 1,b). 
Sixteen acrylic metal-reinforced overdenture housings were fabricated on the model and used throughout the experiment. Eightoverdenture housings contain eight standardized polyoxymethylene (POM) clips and the others contain eight clips made from polyetheretherketon (PEEK). The metal framework contained 3 metal loops attached at midline labially and second molar areas bilaterally(Fig:2-a,b), (fig 3-a,b).The overdenture housings were connected to the analogues with metal bar or (PEEK) bar attachments.

Three $17-\mathrm{cm}$ metal chains were connected to the 3 metal loops. A metal plate with three tapped openings (holes) was attached to the chains by screws. Another chain was screwed into the center of the metal plate to unite the plate with its three chains to the head of a universal testing machine(Fig:4). The universal testing machine was used to test retentive force for each experimental overdenture at

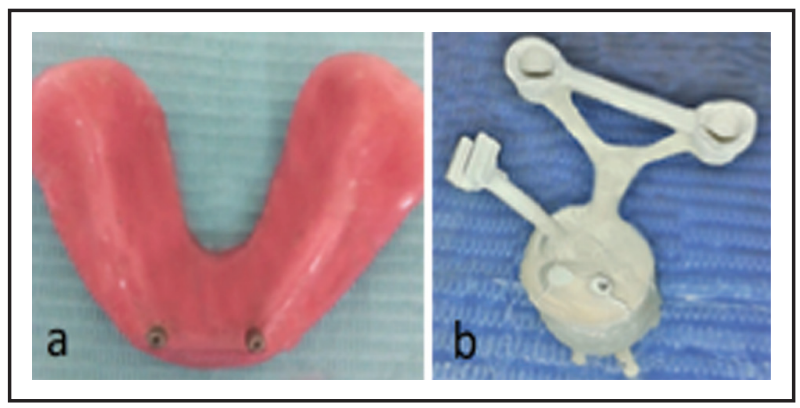

Fig. (1) (a): Implants inserted in the acrylic resin model with dome-shaped abutments. (b): PEEK bar, copings and clip fromBioHPP (Biocompatibility High Performance Polymer)

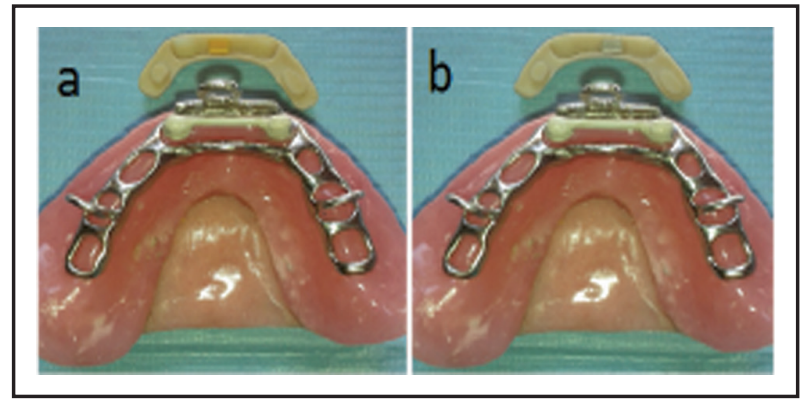

Fig. (3) Attachment system including PEEK bar and overdenture housing with (c): POM clip, (d): PEEK clip. a cross-head speed of $50 \mathrm{~mm} / \mathrm{min}$. This crosshead speed has been reported to approximate clinically relevant movement of the denture away from the edentulous ridge. Loads were applied parallel to the path of insertion until every overdenture housing with clip (female part) separated from its bar attachment (male part).

Maximum load needed to dislodge the experimental overdenture from the mandibular test model (initial retentive force) were calculated. The test was repeated 5 times for each attachment then the mean of initial retentive values (in Newton) was calculated. To simulate repeated insertions and removals of the overdenture over a 3, 6, 9 and 12 months periods (assuming three daily removals and insertions of the overdenture for the purpose of hygiene), each overdenture was pulled out at 270 , 540, 810 and 1080 dislodgment cycles. All results were subjected to statistical analysis.

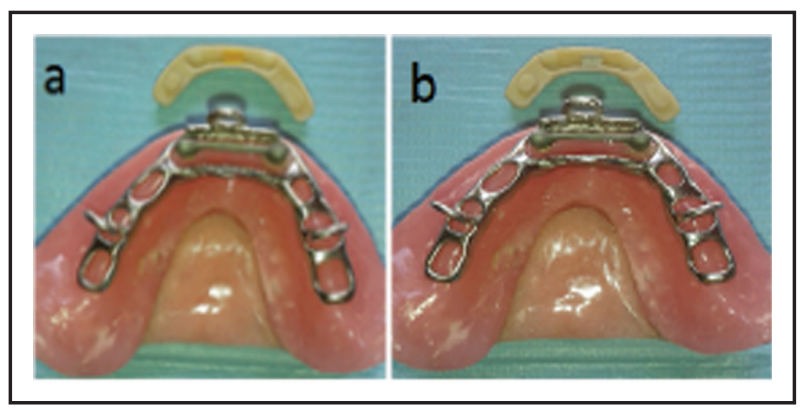

Fig. (2) Attachment system including metal bar and overdenture housing with (a) POM clip, (b): PEEK clip.

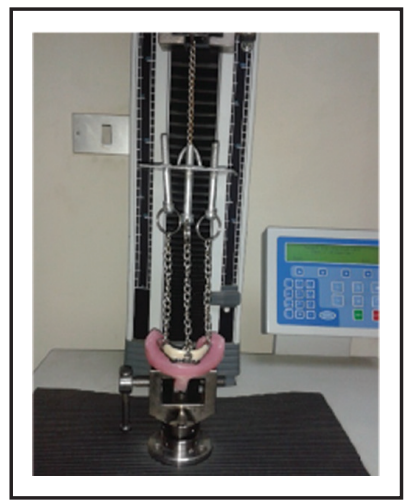

Fig. (4) A metal plate with three tapped openings was attached to the chains by screws and attached to universal testing machine by another chain 


\section{RESULTS}

AfterZero cycles: A statistically significant difference was found between (Metal bar and POM clip), (Metal bar and PEEK clip), (PEEK bar and POM clip) and (PEEK bar and PEEK clip) where $(\mathrm{p} \leq 0.001)$.

A statistically significant difference was found between (Metal bar and POM clip) on one hand and each of (Metal bar and PEEK clip) and (PEEK bar and PEEK clip) on the other hand where $(\mathrm{p}=0.001)$ and $(\mathrm{p} \leq 0.001)$ respectively. While no statistically significant difference was found between (Metal bar and POM clip) and (PEEK bar and POM clip) where $(\mathrm{p}=0.652)$.

Also a statistically significant bar and PEEK clip) and (PEEK bar and POM clip) where ( $\mathrm{p}=0.007)$. While no statistically significant difference was found between (Metal bar and PEEK clip) and (PEEK bar and PEEK clip) where $(\mathrm{p}=0.065)$.

A statistically significant difference was found between (PEEK bar and POM clip) and (PEEK bar and PEEK clip) where ( $\mathrm{p} \leq 0.001)$.The highest mean value of retention was found in (PEEK bar and PEEK clip) (14.10 \pm 0.71$)$ followed by (Metal bar and PEEK clip) $(12.26 \pm 1.62)$ and (PEEK bar and POM clip) $(9.65 \pm 0.94)$ while the least mean value of retention was found in (Metal bar and POM clip) $(8.86 \pm 0.73)$.

After 270 cycles: A statistically significant difference was found between (Metal bar and POM clip), (Metal bar and PEEK clip), (PEEK bar and POM clip) and (PEEK bar and PEEK clip) where $(\mathrm{p} \leq 0.001)$.

A statistically significant difference was found between (Metal bar and POM clip) on one hand and each of (Metal bar and PEEK clip), (PEEK bar and POM clip) and (PEEK bar and PEEK clip) on the other hand where $(\mathrm{p}=0.001),(\mathrm{p}=0.002)$ and $(\mathrm{p} \leq 0.001)$ respectively.
No statistically significant difference was found between (Metal bar and PEEK clip) on one hand and each of (PEEK bar and POM clip) and (PEEK bar and PEEK clip) on the other hand where $(\mathrm{p}=0.999)$ and $(\mathrm{p}=0.118)$ respectively.

Also no statistically significant difference was found between (PEEK bar and POM clip) and (PEEK bar and PEEK clip) where ( $\mathrm{p}=0.095)$. The highest mean value of retention was found in (PEEK bar and PEEK clip) (9.65 \pm 0.54$)$ followed by (Metal bar and PEEK clip) $(8.90 \pm 0.19)$ and (PEEK bar and POM clip) $(8.86 \pm 0.68)$ while the least mean value of retention was found in (Metal bar and POM clip) $(7.45 \pm 0.41)$.

After 540 cycles: A statistically significant difference was found between (Metal bar and POM clip), (Metal bar and PEEK clip), (PEEK bar and POM clip) and (PEEK bar and PEEK clip) where $(\mathrm{p} \leq 0.001)$.

A statistically significant difference was found between (Metal bar and POM clip) on one hand and each of (Metal bar and PEEK clip), (PEEK bar and POM clip) and (PEEK bar and PEEK clip) on the other hand where $(\mathrm{p} \leq 0.001),(\mathrm{p}=0.001)$ and $(\mathrm{p} \leq 0.001)$ respectively.

No statistically significant difference was found between (Metal bar and PEEK clip) and (PEEK bar and POM clip) where $(p=0.218)$ while a statistically significant difference was found between (Metal bar and PEEK clip) and (PEEK bar and PEEK clip) where $(\mathrm{p}=0.014)$.

A statistically significant difference was found between (PEEK bar and POM clip) and (PEEK bar and PEEK clip) where $(\mathrm{p} \leq 0.001)$.The highest mean value of retention was found in (PEEK bar and PEEK clip) (9.22 \pm 0.31$)$ followed by (Metal bar and PEEK clip) $(8.10 \pm 0.24)$ and (PEEK bar and POM clip) (7.45 \pm 0.83$)$ while the least mean value of retention was found in (Metal bar and POM clip) $(5.95 \pm 0.39)$. 
After 810 cycles: A statistically significant difference was found between (Metal bar and POM clip), (Metal bar and PEEK clip), (PEEK bar and POM clip) and (PEEK bar and PEEK clip) where ( $\mathrm{p} \leq 0.001)$.

A statistically significant difference was found between (Metal bar and POM clip) on one hand and each of (Metal bar and PEEK clip) and (PEEK bar and PEEK clip) on the other hand where $(\mathrm{p} \leq 0.001)$ and $(\mathrm{p} \leq 0.001)$ respectively. While no statistically significant difference was found between (Metal bar and POM clip) and (PEEK bar and POM clip) where $(\mathrm{p}=0.286)$.

A statistically significant difference was found between (Metal bar and PEEK clip) on one hand and each of (PEEK bar and POM clip) and (PEEK bar and PEEK clip) on the other hand where $(p \leq 0.001)$ and $(\mathrm{p}=0.012)$ respectively.

A statistically significant difference was found between (PEEK bar and POM clip) and (PEEK bar and PEEK clip) where $(p \leq 0.001)$. The highest mean value of retention was found in (PEEK bar and PEEK clip) (8.89 \pm 0.44$)$ followed by (Metal bar and PEEK clip) $(7.83 \pm 0.19)$ and (PEEK bar and POM clip) (5.93 \pm 0.65$)$ while the least mean value of retention was found in (Metal bar and POM clip) (5.37 \pm 0.46$)$.
After 1080 cycles: A statistically significant difference was found between (Metal bar and POM clip), (Metal bar and PEEK clip), (PEEK bar and POM clip) and (PEEK bar and PEEK clip) where $(\mathrm{p} \leq 0.001)$.

A statistically significant difference was found between (Metal bar and POM clip) on one hand and each of (Metal bar and PEEK clip) and (PEEK bar and PEEK clip) on the other hand where $(\mathrm{p} \leq 0.001)$ and $(\mathrm{p} \leq 0.001)$ respectively. While no statistically significant difference was found between (Metal bar and POM clip) and (PEEK bar and POM clip) where $(\mathrm{p}=0.755)$.

A statistically significant difference was found between (Metal bar and PEEK clip) and (PEEK bar and POM clip) where ( $\mathrm{p} \leq 0.001)$ while no statistically significant difference was found between (Metal bar and PEEK clip) and (PEEK bar and PEEK clip) where $(\mathrm{p}=0.677)$.

A statistically significant difference was found between (PEEK bar and POM clip) and (PEEK bar and PEEK clip) where $(\mathrm{p} \leq 0.001)$. The highest mean value of retention was found in (PEEK bar and PEEK clip) $(9.27 \pm 0.57)$ followed by (Metal bar and PEEK clip) $(8.95 \pm 0.52)$ and (PEEK bar and POM clip) $(5.45 \pm 0.41)$ while the least mean value of retention was found in (Metal bar and POM clip) $(5.16 \pm 0.20)$ (Table 1, 2), (Fig 5, 6).

Table (1): The mean, standard deviation (SD) values of retention of bar and clip type attachment materials in different cycles number

\begin{tabular}{|c|c|c|c|c|c|c|c|c|c|c|}
\hline \multirow{2}{*}{ Variables } & \multicolumn{2}{|c|}{ Zero cycles } & \multicolumn{2}{|c|}{270 cycles } & \multicolumn{2}{|c|}{540 cycles } & \multicolumn{2}{|c|}{810 cycles } & \multicolumn{2}{|c|}{1080 cycles } \\
\hline & Mean & SD & Mean & SD & Mean & SD & Mean & SD & Mean & SD \\
\hline $\begin{array}{l}\text { Metal bar and } \\
\text { POM clip }\end{array}$ & $8.861^{\mathrm{a}}$ & 0.731 & $7.453^{\mathrm{a}}$ & 0.417 & $5.954^{\mathrm{a}}$ & 0.396 & $5.371^{\mathrm{a}}$ & 0.463 & $5.167^{\mathrm{a}}$ & 0.206 \\
\hline $\begin{array}{l}\text { Metal bar and } \\
\text { PEEK clip }\end{array}$ & $12.263^{\mathrm{b}}$ & 1.628 & $8.904^{b}$ & 0.199 & $8.103^{b}$ & 0.242 & $7.837^{\mathrm{b}}$ & 0.193 & $8.954^{\mathrm{b}}$ & 0.525 \\
\hline $\begin{array}{l}\text { PEEK bar and } \\
\text { POM clip }\end{array}$ & $9.656^{\mathrm{a}}$ & 0.948 & $8.866^{\mathrm{b}}$ & 0.689 & $7.457^{\mathrm{b}}$ & 0.837 & $5.936^{\mathrm{a}}$ & 0.658 & $5.451^{\mathrm{a}}$ & 0.411 \\
\hline $\begin{array}{l}\text { PEEK bar and } \\
\text { PEEK clip }\end{array}$ & $14.105^{\mathrm{b}}$ & 0.712 & $9.657^{\mathrm{b}}$ & 0.550 & $9.221^{\mathrm{c}}$ & 0.310 & $8.899^{\mathrm{c}}$ & 0.446 & $9.276^{\mathrm{b}}$ & 0.571 \\
\hline p-value & \multicolumn{2}{|c|}{$\leq 0.001 *$} & \multicolumn{2}{|c|}{$\leq 0.001 *$} & \multicolumn{2}{|c|}{$\leq 0.001 *$} & \multicolumn{2}{|c|}{$\leq 0.001 *$} & \multicolumn{2}{|c|}{$\leq 0.001 *$} \\
\hline
\end{tabular}

Mean with different letters in the same column indicate statistically significance difference

*; significant $(\mathrm{p}<0.05) \quad \mathrm{ns}$; non-significant $(\mathrm{p}>0.05)$ 


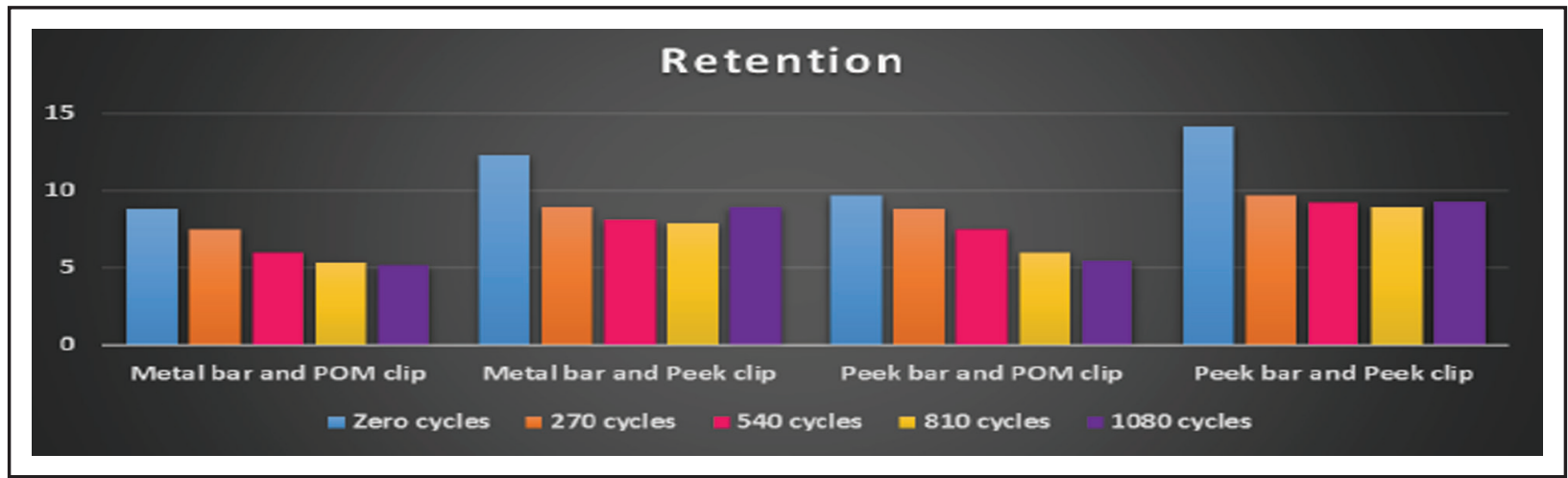

Fig. (5) Bar chart representing retention of bar and clip type attachment materials in different cycle's number

Table (2): The mean, standard deviation (SD) values of retention regardless of cycle's number

\begin{tabular}{|c|c|c|}
\hline \multirow{2}{*}{ Material type } & \multicolumn{2}{|c|}{ Retention } \\
\cline { 2 - 3 } & Mean & SD \\
\hline Metal bar and POM clip & $6.645^{\mathrm{a}}$ & 1.525 \\
\hline Metal bar and PEEK clip & $9.212^{\mathrm{b}}$ & 1.770 \\
\hline PEEK bar and POM clip & $7.473^{\mathrm{a}}$ & 1.785 \\
\hline PEEK bar and PEEK clip & $10.294^{\mathrm{b}}$ & 2.071 \\
\hline p-value & \multicolumn{2}{|c|}{$\leq \mathbf{0 . 0 0 1}{ }^{*}$} \\
\hline
\end{tabular}

Mean with different letters in the same column indicate statistically significance difference

*; significant $(p<0.05)$

$n s$; non-significant $(p>0.05)$

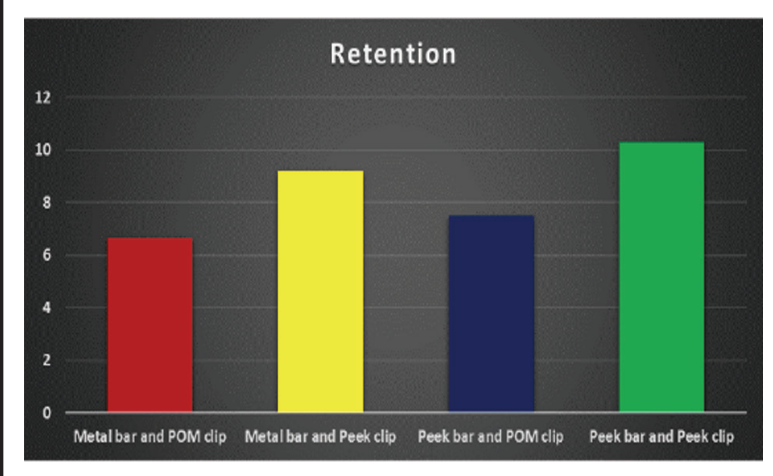

Fig. (6) Bar chart representing retention regardless of cycle's number

\section{DISCUSSION}

The initial retentive forces values in this study were $8.86 \pm 0.73,12.26 \pm 1.62, \quad 9.65 \pm 0.94$ and $14.10 \pm 0.71 \mathrm{~N}$ for (Metal bar and POM clip), (Metal bar and PEEK clip), (PEEK bar and POM clip) and (PEEK bar and PEEK clip) respectively. These values are categorized as "medium or low retention" following the classification of Chung et al. ${ }^{(20)}$ These retention forces are similar to the results of ball attachments ${ }^{(21)}$ and approximates the range measured for other bar systems using POM clips. ${ }^{(15,22)}$

With other studies, much higher values of $20 \mathrm{~N}$ up to $35 \mathrm{~N}$ were reached using POM or metal clips on bars ${ }^{(14,23)}$ So, differences of retention.

Forces between the present study and the literature are probably the result of the study setup with different length of clips and may be due to retention measured in the current study using vertical dislodging from the center of mandibular overdenture (when the 3 chains were connected), while in the aforementioned studies the authors measured the retention by applying the vertical dislodging forces directly above the attachments and implants inserted in acrylic resin blocks.

In the present study, after 12 months of clinical simulation, the retention force values decreased to about $25-40 \%$. This is comparable with the percentage of decrease found in attachments 
$(10-40 \%)$ described in recent literature. ${ }^{(24,25)}$ Nevertheless, there are also some data in recent literature showing retentive elements that changed resulting in a minimal decrease or even slight increase in their retentive values after 3 up to 12 months. ${ }^{(14,26)}$

A study ${ }^{(15)}$ compared retentive forces of metal bars with metal clips on the one hand with metal bars and plastic clips on the other and found that both systems provide retentive forces between 10 and $14 \mathrm{~N}$. also another studies ${ }^{(27,28)}$ reported reduced retention strength values in components of overdenture attachment systems.

Conversely, many studies have demonstrated that retention force values can increase instead of decrease. It has been suggested that this increase is due to deformation of POM components that results in their hardening ${ }^{(29)}$ or to an increase in surface roughness after initial usage. ${ }^{(30)}$ some authors ${ }^{(31)}$ observed from microscopical examination that POM, silicone or nylon components are deformed by forces generated during fatigue tests, which could increase retention force values. Another probable reason for this increase could be thermal expansion of the POM during the test. In addition, oral environment, saliva composition and temperature could also influence results. ${ }^{(23)}$

The advantage of PEEK material compared with POM material could be demonstrated during the simulation period of 12 months. Both materials showed an in vitro acceptable results toward retention force however, the PEEK material showed more resistance to wear than POM material especially when PEEK clips were used with metal or PEEK bars as it was observed from results that retention force values for these types decreased after 540 cycles then, stabilized and slightly increased after 1080 cycles of vertical dislodgment. Further studies are indicated, to evaluate the long-term in vitro and clinical performance of clips made of PEEK compared with those made of POM.
Under clinical conditions, horizontal and oblique strengths, as well as mastication and other forces, including parafunction, can occur, although they were not simulated in this in vitro study. Therefore, the fatigue test, consisting of insertion and removal of overdenture components along the long axis of the implant, may not be the principal cause of reduced retention strength values, nor would the cycling motion likely be responsible for failure of system components. ${ }^{(32)}$

The testing here was directed at limited, specific, and expected mechanical conditions, and this in vitro protocol undoubtedly falls short of clinical reality. Furthermore, simulation of such factors is difficult in an in vitro study, and those factors are better evaluated in clinical trials. Although in vitro studies differ from clinical studies, they allow standardization of the tests by excluding oral conditions and therefore, they provide important information. ${ }^{(20)}$

Additional in vitro experimentation addressing the retentive characteristics of implant overdenture attachments should involve thermal cycling, variable fluid environments, and multidirectional force application, load-unload conditions, and the effects of fatigue on material properties. Ultimately, shortterm and long-term clinical trials should be accomplished to critically assess the attachment systems evaluated in this laboratory investigation. ${ }^{(20)}$

Despite these limitations, this laboratory study showed valid results comparable with those observed in the literature. The bar and clip attachment systems with different materials evaluated in the present study may be considered adequate for clinical usage, as retention force values were higher than the value considered minimal $(5 \mathrm{~N})$ for overdenture retention.

\section{CONCLUSIONS}

Within the limitations of this study, the following conclusions were drawn: 
1. Attachments generally demonstrated significantly decreased retention strength values as the cycle's number increased.

2. The invitro performance of retentive clips made of PEEK is superior to those made of POM, that is, the highest mean value of retention was found in (PEEK bar and PEEK clip) followed by (Metal bar and PEEK clip) and (PEEK bar and POM clip) while the least mean value of retention was found in (Metal bar and POM clip).

3. POM as well as PEEK materials may fulfill the requirements ofretentive clips on metal or PEEK bars.

\section{REFERENCES}

1. Carlsson GE, Omar R. The future of complete dentures in oral rehabilitation.A critical review.J Oral Rehabil. 2010 Feb; 37(2):143-56.

2. Tallgren A. The continuing reduction of the residual alveolar ridges in complete denture wearers: a mixedlongitudinal study covering 25 years. 1972. J Prosthet Dent. 2003 May;89(5):427-35.

3. Cawood JI, Howell RA. Reconstructive preprosthetic surgery. I. Anatomical considerations. Int J Oral Maxillofac Surg. 1991 Apr;20(2):75-82.

4. Grant BT, Kraut RA. Dental implants in geriatric patients: a retrospective study of 47 cases. Implant Dent. 2007 Dec;16(4):362-8.

5. Stellingsma K, Slagter AP, Stegenga B, Raghoebar GM, Meijer HJ. Masticatory function in patients with an extremely resorbed mandible restored with mandibular implant-retained overdentures: comparison of three types of treatment protocols. J Oral Rehabil. 2005 Jun;32(6): 403-10.

6. Burns DR. Mandibular implant overdenture treatment: consensus and controversy. J Prosthodont. 2000 Mar; 9(1):37-46.

7. Raghoebar GM, Meijer HJ, van 't Hof M, Stegenga B, Vissink A. A randomized prospective clinical trial on the effectiveness of three treatment modalities for patients with lower denture problems.A 10 year follow-up study on patient satisfaction.Int J Oral Maxillofac Surg. 2003 Oct;32(5):498-503.
8. Evtimovska E, Masri R, Driscoll CF, Romberg E. The change in retentive values of locator attachments and hader clips over time. J Prosthodont. 2009 Aug;18(6):479-83.

9. Bayer S, Komor N, Kramer A, Albrecht D, Mericske-Stern R, Enkling N. Retention force of plastic clips on implant bars: a randomized controlled trial. Clin Oral Implants Res. 2012 Dec;23(12):1377-84.

10. Walton JN, Huizinga SC, Peck CC. Implant angulation: a measurement technique, implant overdenture maintenance, and the influence of surgical experience. Int J Prosthodont. 2001 Nov-Dec;14(6):523-30.

11. Preiskel HW.Overdentures made easy: a guide to implant and root supported prostheses: Quintessence Publishing Company; 1996.

12. Michalakis KX, Hirayama H, Garefis PD. Cementretained versus screw-retained implant restorations: a critical review. Int J Oral Maxillofac Implants. 2003 SepOct; 18(5):719-28.

13. Fromentin O, Lassauzay C, Abi Nader S, Feine J, de Albuquerque Junior RF. Testing the retention of attachments for implant overdentures - validation of an original force measurement system. J Oral Rehabil. 2010 Jan;37(1):54-62.

14. van Kampen F, Cune M, van der BiltA, Bosman F. Retention and postinsertion maintenance of bar-clip, ball and magnet attachments in mandibular implant overdenture treatment: an in vivo comparison after 3 months of function. Clin Oral Implants Res. 2003 Dec;14(6):720-6.

15. Walton JN, Ruse ND. In vitro changes in clips and bars used to retain implant overdentures. J Prosthet Dent. 1995 Nov;74(5):482-6.

16. Bayer S, Grüner M, Keilig L, Hültenschmidt R, Nicolay C, Bourauel C, Utz KH, Stark H. Investigation of the wear of prefabricated attachments--an in vitro study of retention forces and fitting tolerances. Quintessence Int. 2007 May;38(5):e229-37.

17. Arda T, Arikan A. An in vitro comparison of retentive force and deformation of acetal resin and cobalt-chromium clasps. J Prosthet Dent. 2005 Sep;94(3):267-74.

18. Ma R, Tang T. Current strategies to improve the bioactivity of PEEK. Int J Mol Sci. 2014 Mar 28;15(4):5426-45.

19. Nieminen T, Kallela I, Wuolijoki E, Kainulainen $H$, Hiidenheimo I, Rantala I. Amorphous and crystalline polyetheretherketone: Mechanical properties and tissue reactions during a 3-year follow-up. J Biomed Mater Res A. 2008 Feb;84(2):377-83. 
20. Chung KH, Chung CY, Cagna DR, Cronin RJ Jr. Retention characteristics of attachment systems for implant overdentures.J Prosthodont. 2004 Dec; 13(4):221-6.

21. Abi Nader S, de Souza RF, Fortin D, De Koninck L, Fromentin O, Albuquerque Junior RF. Effect of simulated masticatory loading on the retention of stud attachments for implant overdentures. J Oral Rehabil. 2011 Mar; 38(3):157-64.

22. Williams BH, Ochiai KT, Hojo S, Nishimura R, Caputo AA. Retention of maxillary implant overdenture bars of different designs. J Prosthet Dent. 2001 Dec;86(6):603-7.

23. Botega DM, Mesquita MF, Henriques GE, Vaz LG. Retention force and fatigue strength of overdenture attachment systems. J Oral Rehabil. 2004 Sep; 31(9):884-9.

24. Rutkunas V, Mizutani H, Takahashi H. Evaluation of stable retentive properties of overdenture attachments. Stomatologija. 2005;7(4):115-20.

25. de Sousa AA, Mattos BS. Magnetic retention and bar-clip attachment for implant-retained auricular prostheses: a comparative analysis. Int J Prosthodont. 2008 May-Jun; 21(3):233-6.

26. Naert I, Gizani S, Vuylsteke M, Van Steenberghe D. A 5-year prospective randomized clinical trial on the influence of splinted and unsplinted oral implants retaining a mandibular overdenture: prosthetic aspects and patient satisfaction. J Oral Rehabil. 1999 Mar;26(3):195-202.

27. Breeding LC, Dixon DL, Schmitt S. The effect of simulated function on the retention of bar-clip retained removable prostheses. J Prosthet Dent. 1996 May;75(5):570-3.

28. Epstein DD, Epstein PL, Cohen BI, Pagnillo MK. Comparison of the retentive properties of six prefabricated post overdenture attachment systems.J Prosthet Dent. 1999 Nov; 82(5):579-84

29. Gamborena JI, Hazelton LR, NaBadalung D, Brudvik J. Retention of ERA direct overdenture attachments before and after fatigue loading.Int J Prosthodont. 1997 Mar-Apr; $10(2): 123-30$.

30. Setz I, Lee SH, Engel E. Retention of prefabricated attachments for implant stabilized overdentures in the edentulous mandible: an in vitro study. J Prosthet Dent. 1998 Sep;80(3):323-9.

31. Fromentin O, Picard B, Tavernier B. In vitro study of the retention and mechanical fatigue behavior of four implant overdenture stud-type attachments. Pract Periodontics Aesthet Dent. 1999 Apr; 11(3):391-7; quiz 398.

32. Pigozzo MN, Mesquita MF, Henriques GE, Vaz LG. The service life of implant-retained overdenture attachment systems.J Prosthet Dent. 2009 Aug;102(2):74-80. 